\title{
AAVALIAÇÃO DE UM CONTRATO DE GESTÃO: QUANDO O SER ENCONTRA O DEVER SER - UM OLHAR LÓGICO- JURÍDICO SOBRE UM INSTRUMENTO DA CIÊNCIA DA ADMINISTRAÇÃO
}

\section{Gilberto Torres Alves Júnior*}

Sumário: 1 Introdução; $2 \mathrm{O}$ contrato de gestão; 3 A avaliação; 4 O ser e o dever ser; $5 \mathrm{O}$ encontro; 6 Julgados envolvendo a avaliação dos contratos de gestão; 7 Conclusão.

Resumo: O presente artigo objetiva abordar, sob o ponto de vista lógicosemântico, o relatório de avaliação dos contratos de gestão firmado entre o Poder Público e as Organizações Sociais, especialmente da área da saúde no estado de Goiás, realizando o entrelaçamento, por meio da lógica jurídica, entre o relatório e seus efeitos, demonstrando que a peça pertence ao mundo do "ser" enquanto os efeitos ao do "dever ser", sendo, portanto, o conector entre os dois mundos.

Palavras-chave: Contrato de gestão. Relatório de avalição. Ser e dever ser. 


\section{Introdução}

A reforma da Administração promovida pelo extinto Ministério da Administração e Reforma do Estado (MARE), introduziu no ordenamento jurídico nacional as Organizações Sociais (OS), pessoas jurídicas de direito privado, sem fins lucrativos, com campo de atuação nas áreas de saúde, educação, preservação do meio ambiente, pesquisas científicas e cultura, que, após o cumprimento de certos requisitos, poderiam ser qualificadas como tal.

A justificativa jurídica para que o Estado fomente as atividades realizadas pelas OSs é o princípio da subsidiariedade, entendido como aquele em que o Estado somente deverá agir nas ações em que a sociedade organizada, por si, não consegue realizar (ALBUQUERQUE, 2008, p. 37).

Para dar efetividade ao disposto no art. 196 e, especialmente, o prescrito no $\S 1^{\circ}$ do art. 199 da Constituição Federal, ante a incapacidade e impossibilidade da Administração Pública de fornecer diretamente os serviços de saúde, tornou-se política pública o fomento de parcerias público-privadas com as OSs, não se excluindo outras formas de cooperação entre o Estado e a sociedade.

$\mathrm{Na}$ área da saúde, diversos entes da Federação aprovaram o ordenamento jurídico necessário para o fomento das atividades das OSs, criando a necessidade de fortalecer seus órgãos responsáveis pela avaliação, especialmente dos contratos de gestão.

O resultado da avaliação gera diversas implicações, sejam de ordem jurídica, administrativa ou fática, conforme se verá no presente artigo, após observação empírica na Secretaria de Saúde do Estado de Goiás, demonstrando que existe a necessidade dos operadores do Direto terem um olhar lógico-jurídico do produto da avaliação.

\section{O contrato de gestão}

A qualificação das pessoas jurídicas de direito privado como OS é regulamentada na Administração Federal pela Lei no 9.637/1998 e no estado de Goiás pela Lei Estadual n ${ }^{\circ} 15.503 / 2005$, não existindo nenhuma inovação na lei local em relação à federal.

$\mathrm{O}$ instrumento jurídico que gere as relações entre o ente contratante e a OS contratada é o Contrato de Gestão, uma modalidade de contrato administrativo (DI PIETRO, 2005, p. 294), no qual são definidas as obrigações de cada parte e as metas a serem alcançadas pela organização social, variando os tipos de meta, conforme a área de atuação da entidade, 
forma de remuneração, sanções pelo inadimplemento, meios de prestação de contas e avaliação do desempenho da OS, sanções e prazo de vigência.

Di Pietro (2011, p. 256) preleciona que essa modalidade de avença é "inspirado no direito estrangeiro, adaptando-se mal à rigidez de nosso direito positivo", discorrendo um pouco sobre a matriz francesa:

André de Laubadère, Pierre Delvolvé e Frank Moderne (1983:423 ss) cuidam desse contrato sob o título de "contratos discutíveis", explicando que os mesmos revelam a existência de certo acordo, "sem que se possa assegurar nem que eles são verdadeiros contratos, nem que eles não são. Nenhuma das categorias que eles comportam corresponde em si mesma a verdadeiros ou falsos contratos. Cada contrato deve ser examinado isoladamente para que uma resposta ser efetivamente dada.

No caso específico da saúde no estado de Goiás, as OSs gerem unidades de saúde com perfis ${ }^{1}$ diversos e que oferecem serviços ambulatoriais, clínicos e hospitalares de nível secundário e terciário ${ }^{2}$, localizados na capital e em cidades do interior, de forma que em todos os contratos existam, na área assistencial, metas a serem cumpridas quantificadas em procedimentos médicos e não médicos.

Há, ainda, as metas financeiras e de qualidade, com indicadores iguais para todos os contratos, vez que esses parâmetros não dependem do perfil da unidade para serem medidos.

A remuneração do contrato possui uma parte fixa e outra variável, sendo esta última equivalente a $20 \%$ do valor do pagamento mensal, com avaliações semestrais, ou seja, no primeiro semestre de cada novo contrato, a OS percebe $100 \%$ da remuneração, ficando os períodos subsequentes sujeitos ao julgamento feito no relatório de avaliação.

\footnotetext{
1 Os perfis das unidades de saúde são definidos por sua atividade preponderante. Cite-se como exemplo os hospitais de urgências (especializados no primeiro e pronto atendimento do paciente com risco de morte), hospitais gerais (com foco no atendimento ambulatorial e cirúrgico das diversas modalidades clínicas), de reabilitação, de psiquiatria, materno-infantil etc.

2 A atenção à saúde, consoantes definição da Organização Pan-americana de Saúde - OPAS, é dividia em 3 níveis: primário, secundário e terciário. No primeiro é ofertada assistência sanitária essencial (PSF, agente comunitário de saúde etc); secundário: são os sistemas e serviços de tratamento ambulatorial e pequenos hospitais de tecnologia intermediária, que incorpora funções do nível primário e acrescenta as de tratamento especializado, com objetivo de reabilitação. Terciário: é o nível de atenção constituído por grandes hospitais gerais e especializados que concentram tecnologia de maior complexidade e de ponta, servindo de referência para os demais programas, sistemas e serviços.
} 


\section{A avaliação}

Avaliação é a observação e análise sistemática e planejada, com emissão de um juízo de valor acerca de determinado evento ou intervenção (MINAYO, 2005, p. 24), diferindo-se do monitoramento, que apenas observa e constata modificações no evento.

As metodologias avaliativas não são uma novidade no Brasil. Contudo, sua utilização é mais desenvolvida na área educacional, existindo grandes esforços de implementação nas políticas públicas gerais e nas intervenções da saúde, no intuito de subsidiar o gestor nas decisões a serem tomadas na condução da Administração Pública.

Existem várias metodologias de avaliação, variando de acordo com a área de conhecimento, sendo que na área de saúde o mais utilizado é o modelo do Centers for Disease Control and Prevetions - CDC e o modelo Contexto, Insumo, Processo e Produto - CIPP (CRUZ, 2006, p. 7)

Quanto à sua função, as avaliações podem ser classificadas em formativas ou somativas:

\footnotetext{
A primeira refere-se ao estudo dos resultados ou efeitos do programa. Através desta modalidade se determina até que ponto foram cumpridos os objetivos ou produzidos os efeitos previstos. Busca-se determinar o valor de um programa, uma vez que, ao ser desenvolvido, investiga os efeitos comparando-os com as necessidades dos usuários ou beneficiários. A segunda refere-se ao seguimento que se realiza durante o processo de execução de um programa ou projeto. Fornece informação acerca do modo de se desenvolver o referido processo (ALMEIDA, 2006, p. 6).
}

A modalidade utilizada para avaliar os contratos de gestão é a somativa, vez que é um processo periódico e contínuo, com o objetivo de apresentar correções na execução dos serviços assistenciais de saúde.

Desta forma, o órgão encarregado pela avaliação emite relatórios prévios com a primeira opinião sobre o resultado alcançado no período e mostra pontos a serem esclarecidos pela OS antes da emissão do documento opinativo final, oportunizando o contraditório. O relatório final contém recomendações à OS e à Secretaria, e atribui conceitos à gestão da unidade que surtirá efeitos financeiros na parte variável do contrato.

O conceito final do período é calculado por meio de processo aritmético de notas e pesos atribuídos a cada indicador, resultando em uma avaliação com pouquíssimo grau discricionário, em consonância com a metodologia descrita em anexo contratual. 


\section{0 ser e o dever ser}

A dualidade de mundos 'ser' e 'dever ser' já foi objeto de estudo de Immanuel Kant, antes de Georg Henrik von Wright sistematizar o assunto sob o ponto de vista da Lógica Deôntica (CARVALHO, 2009, p. 155), que por sua vez também foi abordado por Hans Kelsen em sua Teoria Pura do Direito.

Segundo Rabenhorst (2005), Kelsen "utilizaria dicotomia entre Sein (ser) e Sollen (dever ser) em quatro níveis distintos: o ontológico, o epistemológico, o lógico-semiótico e o nível modal". Para este estudo importa apenas as abordagens epistemológica e lógico-semiótica.

As condutas humanas podem ser observadas tanto sob o ponto de vista da causalidade natural quanto da normativa. Na primeira, estão os fatos como são, em razão das causalidades naturais, regidas de ciências naturais, tais como nascer, morrer, chover, inundar etc. São eventos sob os quais o homem não pode ter, em tese, um controle, por ocorrerem por força da natureza ou da realidade.

Em prisma diverso "se localizam as ciências normativas, que recebem tal denominação, não porque elas estabelecem normas ou prescrevem um comportamento qualquer, mas porque prescrevem normas" (RABENHORST, 2005).

A ligação entre um campo do conhecimento e outro ocorre quando se aplica a abordagem lógico-semiótico aos fatos, ou seja, é necessário um conector entre esses dois mundos - ou corpos de linguagem no entender de Paulo de Barros Carvalho - para que haja a implicação entre um e outro de forma que a proposição-causa se atrele à proposição-efeito, ou seja, haja um nexo de causalidade.

Carvalho (2009, p. 159), assim preleciona:

No mundo do "dever-ser" a implicação é utilizada. As proposições, implicantes e implicadas são atreladas, não por um ato de conhecimento, mas por um ato de autoridade. O legislador, com a finalidade de direcionar condutas intersubjetivas, emprega o vínculo implicacional, associando um fato a uma consequência, para alcançar tal finalidade. Por isso, dizemos ser ele utilizado e não mencionado. A relação entre as proposições da linguagem em que se manifesta o direito não estabelece na forma "S é P", como na linguagem da realidade física, pois são prescritas do mundo circundante. Ela aparece na fórmula "S deve ser P" que, em termos totalmente formais, se representa: " $\mathrm{D}(\mathrm{S} \rightarrow \mathrm{P})$ " (deve ser que $\mathrm{S}$ implique $\mathrm{P})$. A causalidade é estatuída. E por um ato de vontade da autoridade que legisla, de prescrever condutas, que o termohipótese se encontra ligado ao termo-tese e não por um ato de conhecimento. As leis do direito não dizem como as coisas do mundo são, ou como os fenômenos se dão, elas descrevem condutas intersubjetivas. 
Esta estrutura lógico-semântica é a base de toda linguagem da ciência do direito, que tem natureza prescritiva, enquanto que a das ciências naturais é descritiva.

O tema é longo e exerce um fascínio no estudioso da Teoria Geral do Direito, mas para o escopo deste trabalho, essa pincelada é suficiente para o desenvolvimento do raciocínio proposto desde o início do artigo.

\section{0 encontro}

Na elaboração dos contratos de gestão, especialmente no quadro das metas assistenciais, os técnicos da Secretaria recorreram, basicamente, a três sistemas de informações criados e mantidos pelo Departamento de Informática do SUS - DATASUS ${ }^{3}$ : SIA ${ }^{4}, \mathrm{SIH}^{5}$ e Tabnet ${ }^{6}$. No primeiro sistema é possível analisar os procedimentos de caráter ambulatorial; no segundo, os procedimentos hospitalares e, no último, emitir relatórios de perfil epidemiológico.

Os dados podem ser analisados em diversos níveis geográficos, do local (unidade de saúde ou por município) até o nacional, mais genérico e consequentemente com maior probabilidade de distorção em razão das leis específicas da estatística.

Uma vez realizado o estudo da região onde a unidade de saúde a ser gerida pela OS está localizada, traça-se seu perfil e recorre-se, ainda, a outro sistema de informação, denominado SisPPI, que possui os dados da Pactuação Programada e Integrada - PPI.

A PPI foi introduzida no SUS por meio da Norma Operacional

\footnotetext{
3 Os dados DATASUS é acessível a qualquer cidadão no sítio <http://www.datasus.gov.br $>$ no qual disponibiliza as informações de caráter público. Todavia, informações mais específica do módulo SIH/SUS - Sistema de Informações Hospitalares só podem ser acessados por técnicos previamente cadastrados porque remetem a dados pessoais dos pacientes atendidos pelo SUS, especialmente as AIH - Autorização de Internação Hospitalar, nas quais contém nome, endereço e o rol de procedimentos feitos no usuário e pagos pelo SUS.

4 SIA/SUS - Sistema de Informações Ambulatoriais do SUS. Sistema desenvolvido e mantido pelo DATASUS para apresentação e processamento dos procedimentos ambulatoriais das unidades de saúde. Não é possível o detalhamento dos procedimentos por paciente.

5 SIH/SUS - Sistema de Informações Hospitalares do SUS. Sistema desenvolvimento e mantido pelo SUS para apresentação e processamento do faturamento das unidades de saúde. É possível o detalhamento dos procedimentos realizados em cada paciente, por meio do espelho da AIH Autorização de Internação Hospitalar, que depende acesso privativa aos técnicos do DATASUS e responsável pelos sistemas do SUS em âmbito estadual e municipal.

6 Tabnet - Módulo web do TabSUS. Sistema desenvolvido e mantido pelo DATASUS onde é armazenado os dados epidemiológicos da população brasileira com base na produção apresentada e processada pelo SIA/SIH e SISPAC.
} 
Básica ${ }^{\circ} 1$ - NOB/1996, aprovada pela Portaria GM/MS nº 2.203, de 5 de novembro de 1996, conceituando o instrumento da seguinte forma:

11.1.1. A PPI envolve as atividades de assistência ambulatorial e hospitalar, de vigilância sanitária e de epidemiologia e controle de doenças, constituindo um instrumento essencial de reorganização do modelo de atenção e da gestão do SUS, de alocação dos recursos e de explicitação do pacto estabelecido entre as três esferas de governo. Essa Programação traduz as responsabilidades de cada município com a garantia de acesso da população aos serviços de saúde, quer pela oferta existente no próprio município, quer pelo encaminhamento a outros municípios, sempre por intermédio de relações entre gestores municipais, mediadas pelo gestor estadual.

$[\ldots]$

11.1.3. A elaboração da PPI deve se dar num processo ascendente, de base municipal, configurando, também, as responsabilidades do estado na busca crescente da equidade, da qualidade da atenção e na conformação da rede regionalizada e hierarquizada de serviços.

11.1.4. A Programação observa os princípios da integralidade das ações de saúde e da direção única em cada nível de governo, traduzindo todo o conjunto de atividades relacionadas a uma população específica e desenvolvidas num território determinado, independente da vinculação institucional do órgão responsável pela execução destas atividades. Os órgãos federais, estaduais e municipais, bem como os prestadores conveniados e contratados têm suas ações expressas na programação do município em que estão localizados, na medida em que estão subordinados ao gestor municipal.

Traçado o perfil da unidade e confrontado com a PPI para os ajustes necessários, elabora-se o quadro de metas assistenciais do contrato de gestão.

Até neste ponto tudo se deu no campo do "ser" porque não existe um conector entre o levantamento feito pelas áreas técnicas com o "dever ser", ou seja, ainda não ocorreu a transposição daquilo que se espera de produção pela unidade de saúde para o campo de obrigação assumida pela OS quando da assinatura do contrato.

No intuito de facilitar o entendimento do raciocínio proposto, colacionase parte de um quadro de metas de uma das unidades de saúde na Tabela 1.

Firmado e outorgado o contrato com a OS, as metas acima descritas se tornam parte do campo do "dever ser", pois a entidade obriga-se a cumprir, mensalmente, os quantitativos de procedimentos. Esse dever não surgiu do nada, mas sim do fato de que a OS declarou ser capaz de realizar o proposto pela Secretaria, mediante o pagamento de determinada quantia e que, caso após a avaliação semestral a que seria submetida fosse constatado o não cumprimento, haveria o desconto do valor mensal a ser repassado. 
Tabela 1 - Metas físicas

\begin{tabular}{|l|c|c|c|}
\hline \multicolumn{1}{|c|}{ LEITOS } & $\begin{array}{c}\text { CAPACIDADE } \\
\text { INSTALADA }\end{array}$ & LEITOS/DIA & META \\
\hline Observação & 18 & 540 & 270 \\
\hline $\begin{array}{l}\text { Internação Clínica } \\
\text { e Cirúrgica }\end{array}$ & 84 & 2520 & 600 \\
\hline UTI Adulto & 10 & 300 & 75 \\
\hline UTI Pediátrica & 10 & 300 & 75 \\
\hline
\end{tabular}

\begin{tabular}{|c|c|}
\hline ATENDIMENTO PRONTO SOCORRO & QUANTIDADE \\
\hline Urgências/Emergências & 5400 \\
\hline
\end{tabular}

\begin{tabular}{|l|c|}
\hline \multicolumn{1}{|c|}{ PROCEDIMENTOS CIRÚRGICOS } & QUANTIDADE \\
\hline Bucomaxilo & 15 \\
\hline Vascular & 20 \\
\hline Neurocirurgia & 12 \\
\hline Cirurgia Geral & 110 \\
\hline Pediatria & 10 \\
\hline Ortopedia/Traumatologia & 280 \\
\hline TOTAL & 450 \\
\hline
\end{tabular}

Fonte: Anexo I do Contrato $n^{\circ}$ 120/2010-SES/GO, já aditado em 2011.

Neste exato ponto torna-se clara a questão da implicação descrita por Carvalho (2009, p. 159), "D(S $\rightarrow P)$ " (deve ser que $S$ implique $P$ ), que traduzindo na linguagem obrigacional do contrato tem-se: a) dever ser que se a OS produzir o pactuado (S) implique no pagamento de $100 \%$ do valor mensal (P); ou b) deve ser que a OS não produzindo as metas pactuadas (S) implica no desconto de valor em seu pagamento mensal (P).

Retornando ao escólio de Carvalho (2009, p. 159), essa preleciona:

No caso, por exemplo, do enunciado citado da menoridade civil, o legislador, diante da realidade social que o cerca, elege o fato "ser menor de 16 anos" e a ela atribui o efeito da incapacidade absoluta, ao tomá-lo como termo-hipótese deste termo-consequente. E por que não elegeu o fato "ser menor de 18 anos"? E por que não the atribuiu a consequência da incapacidade relativa? Porque os vínculos jurídicos se estabelecem exclusivamente por meio de atos de vontade do legislador. $\mathrm{O}$ mesmo fato pode ser atrelado a inúmeras consequências (ex: o fato de um acidente de carro com vítimas atrela-se juridicamente ao recebimento do seguro, à indenização civil, à ação criminal, etc), assim como, 
a mesma consequência pode decorrer de vários fatos (ex: a consequência da incapacidade absoluta pode decorrer juridicamente do fato da deficiência mental e da impossibilidade de manifestação de vontade), isto acontece porque, as relações entre fato-causa e fato-efeito, constantes na linguagem do direito, são postas pelo legislador. A causalidade que o sistema jurídico estabelece é uma relação deonticamente firmada, como diz LOURIVAL VILANOVA, "o efeito não segue sempre o fato, mas, dado o fato jurídico, deve ser o seu efeito".

Recordando Di Pietro (2011, p. 256), que cita que alguns doutrinadores franceses denominam o contrato de gestão como "contrato discutível", que revela acordos os quais devem ser analisados caso a caso.

Eis o ponto onde a avaliação passará a se relacionar com os campos do "ser" e do "dever ser". Considerando aquela como atividade na qual se emite um juízo de valor sobre uma intervenção, após observação e análise sistemática (MINAYO, 2005, p. 24) e, dentro da sistemática da Secretaria, a avaliação ocorre no semestre seguinte à execução do serviço (fato-causa), o relatório apontará o cumprimento ou não das metas contratadas (fato-efeito).

O produto da avaliação, que é o relatório conclusivo, dentro da sistemática lógico-semântica é um fato, mas qual a modalidade, fato-causa ou fato-efeito? Só há espaço para a consideração do relatório como fatocausa não se vislumbrando, a princípio, da possibilidade sê-lo fato-efeito.

O relatório de avaliação é um documento que apenas apresenta a narração de uma situação, comparando-a com parâmetro para, então, concluir algo, emitindo-se um juízo de valor. É uma peça encadeada na lógica formal, do tipo verdadeiro ou falso, não de lógica deôntica, cujos modais são permitido, proibido ou obrigado.

Apesar de existir a expressão "juízo de valor" no conceito de avaliação, esta possui um sentido diverso do adotado dentro da lógica do direito, tanto é assim que a conclusão do relatório é sempre: cumpriu (verdadeiro) ou não cumpriu (falso) as metas. A razão do cumprimento ou não cumprimento, mesmo sendo algo do campo da avaliação, é acessório em relação ao principal.

Desta forma tem-se que, apresentado o relatório com a informação de cumprido ou não cumprido, voltam-se os olhos para o contrato de gestão, peça escrita em linguagem prescritiva, para então no rol das obrigações verificar o que "prescreve" a avença caso haja ou não o cumprimento das metas e aplicar a formalização " $\mathrm{D}(\mathrm{S} \rightarrow \mathrm{P})$ " (deve ser que $\mathrm{S}$ implique $\mathrm{P})$ : a) dever ser que cumprido a meta (S) implique na manutenção do pagamento integral (P); b) dever ser que não cumprida a meta (S) implique na redução do valor do pagamento $(\mathrm{P})$. 
O exemplo acima versa apenas sobre a questão financeira. Contudo, a avaliação do contrato de gestão também gera outras implicações no "dever ser", pois é com base nela que são feitas as correções e ajustes nas metas, ou seja, é com base em um fato-causa (relatório) que se ocorre o fato-efeito (termo aditivo ou repactuação das metas), criando assim uma relação em que o "ser" implica no "dever ser" que na cadeia seguinte valida novamente o "ser".

\section{Julgados envolvendo a avaliação dos contratos de gestão}

Considerando que foi a União quem primeiro instituiu a legislação sobre a qualificação de organizações sociais em maio de 1998, seguido do estado de São Paulo, em junho do mesmo ano, é natural que o Tribunal de Contas da União - TCU e o Tribunal de Contas de São Paulo - TCE/SP tenham apreciado maior número de questões envolvendo a avaliação de contratos de gestão. Desta forma, colacionam-se alguns arestos que tratam da matéria e serão tecido breves comentários sobre cada um, observado o ponto de visto adotado neste trabalho.

O primeiro julgado que se conhece no qual a falta efetiva da avaliação gerou consequências, foi a Decisão 102/1999 - Plenário do TCU:

EMENTA: Auditoria. Associação das Pioneiras Sociais. Acompanhamento de contrato de gestão. Ausência de acompanhamento da execução do contrato pelo Ministério da Saúde. Renovação do contrato sem a devida avaliação final. Objetivos parcialmente cumpridos. Descumprimento de prazo para remessa ao Tribunal de parecer acerca de relatório de cumprimento do contrato. Limitações no sistema de apuração de custos. Impossibilidade de geração de padrões e estatísticas confiáveis com vistas ao controle e avaliação. Ausência de registro específico de bens pertencentes à União. Contratação de auditoria independente para realização de auditoria interna. Ausência de indicadores e padrões para pagamento de vantagens aos empregados. Recomendação. Determinação. Juntada às contas. ${ }^{7}$

Nesse julgamento, a Corte de Contas manifesta-se acerca do contrato de gestão firmado entre o Ministério da Saúde e a Associação das Pioneiras Sociais, gestora da Rede Sarah, unidade de saúde qualificada como Serviço Social Autônomo pela Lei $\mathrm{n}^{\circ} 8.246 / 1991$, e que inspirou os modelos de OS no Brasil, delineando os primeiros entendimentos sobre essa modalidade de avença.

7 TCU, Decisão n 102/1999, relator Min. Humberto Souto. DOU 08-04-1999. 
A primeira conclusão que o aresto aponta é que a falta de um relatório de avaliação conclusivo impede a prorrogação do contrato:

O Tribunal Pleno, diante das razões expostas pelo Relator, DECIDE: 8.1. determinar ao Ministro de Estado da Saúde e à direção da Associação das Pioneiras Sociais - APS que, doravante, na renovação do contrato de gestão, firmado entre a União e a APS, deverá ser observada a condicionante contida no inciso XIV, do art. $3^{\circ}$, da Lei $\mathrm{n}^{\circ} 8.246 / 91$, ou seja, a renovação somente deverá ser feita se a avaliação final da execução do plano plurianual demonstrar a consecução dos objetivos preestabelecidos;

\section{Outro ponto existente no acórdão é a recomendação da adoção de} que a avaliação deverá ser feita com base em metas e índices a serem fixados no contrato de gestão, o que é previsto na redação do inciso I, da Lei $n^{\circ}$ 9.637/1998:

8.3. recomendar ao Ministro de Estado da Saúde a adoção de medidas no sentido de que, quando da fixação negociada do conjunto de indicadores relevantes a serem utilizados na avaliação de desempenho da execução de contratos de gestão no âmbito daquele Ministério, em especial no que se refere ao contrato de que trata a Lei $n^{\circ} 8.246 / 91$, os responsáveis daquele Ministério atentem para a viabilidade de serem tomadas as seguintes medidas: a) elaboração de estudo sobre a adoção de índices e pesos para cada um dos indicadores de desempenho, de modo a aperfeiçoar a avaliação do grau de realização das metas fixadas e permitir maior influência das áreas de atividade mais relevantes no resultado final da análise de desempenho; b) estabelecimento de indicadores e padrões a serem obedecidos quanto à remuneração e vantagens de qualquer natureza atribuíveis aos empregados da Entidade e aos seus diretores; c) fixação de metas físico-financeiras relativas à produção de serviços e aumento da capacidade instalada (expansão da rede), permitindo planejamento de investimento e despesas de custeio, bem como a criação de um instrumento de programação financeira a ser submetido periodicamente ao Ministério da Saúde pela entidade contratada; d) fixação de metas quantificadas a serem atingidas anualmente pela entidade contratada com relação aos programas de execução continuada previstos no plano operacional do contrato de gestão; e) revisão dos indicadores e metas utilizados na avaliação da execução dos contratos de gestão, adequando-os periodicamente a alterações significativas das condições vigentes quando da sua assinatura, mediante repactuação dos índices a serem alcançados, de modo que estes possam efetivamente servir à aferição do desempenho da entidade contratada; f) elaboração de diagnóstico das atividades a serem administradas por meio de contrato de gestão, com o objetivo de subsidiar a definição de indicadores e o acordo sobre os respectivos índices que servirão de parâmetros para a avaliação da execução do contrato; 
No início do relatório do julgado consta que a auditoria operativa ${ }^{8}$ ocorreu de 22 de setembro a 31 de outubro de 1997, ou seja, em período anterior à publicação da lei das OSs, não se podendo auferir se os trâmites internos no TCU influenciaram na redação da Lei n ${ }^{\circ}$ 9.637/1998 ou se essa é quem serviu de espeque para a decisão proposta pelo relator.

Em outra decisão, que julga as contas da Agência Nacional de Vigilância Sanitária - Anvisa, considerada uma agência executiva e que pode firmar contrato de gestão com o ministério ao qual está jurisdicionada, consoante disposto no art. 19, da Lei n ${ }^{\circ}$ 9.782/1999, o TCU questiona a falta dos meios necessários para a avaliação das metas, conforme pactuado na avença:

SUMÁRIO: Prestação de contas. ANVISA. Contrato de Gestão. Metas não alcançadas. Supervisão ministerial deficiente. Descontrole administrativo na concessão de diárias e passagens. Citação. Audiência. Acolhimento de razões de justificativa de alguns responsáveis e rejeição de outros. Determinação para instauração de TCE. Julgamento regular de alguns responsáveis e irregular de outros. Acolhimento de razões de justificativa de alguns responsáveis e rejeição de outros. Multa. Débito. Determinação. Recomendações. Arquivamento. ${ }^{9}$

\section{Consta no relatório uma longa análise acerca da avaliação do contrato} de gestão, do qual se extrai alguns excertos:

29. Dado o modelo de gestão adotado pela autarquia, os dirigentes da entidade firmaram contrato de gestão que formalizou compromisso com os resultados previstos e suas implicações.

30. Em vigência desde 10/9/1999, o contrato de gestão é o principal instrumento de avaliação do desempenho operacional e administrativo da autarquia, conforme dispõe o art. 19 da Lei $\mathrm{n}^{\circ}$ 9.782/1999. O referido contrato "visa o fomento e a execução de atividades na área de vigilância sanitária, com a finalidade promover a proteção da saúde da população brasileira” (fl. 72).

31. A avaliação das metas estabelecidas por meio do contrato de gestão é, portanto, primordial para formação de juízo sobre o desempenho da entidade, em consonância com o disposto na Lei no 9.782/1999:

“Art. 19. A Administração da Agência será regida por um contrato de gestão, negociado entre o seu Diretor-Presidente e o Ministro de Estado da Saúde, ouvidos previamente os Ministros de Estado da Fazenda e do Planejamento, Orçamento e Gestão, no prazo máximo de cento e vinte dias seguintes à nomeação do Diretor-Presidente da autarquia.

8 O TCU adora terminologias para suas modalidades de auditoria diversas das adotadas nas auditorias do SUS. A auditoria operativa, no SUS, é a modalidade em que a equipe de trabalho se desloca in loco para analisar os achados de auditoria, não se cingindo, apenas, à análise documental, denominada de auditoria analítica.

9 TCU, Acórdão 2.572/2010 - Primeira Câmara, relator Auditor Weder de Oliveira. DOU 21-052010. 
Parágrafo único. O contrato de gestão é o instrumento de avaliação da atuação administrativa da autarquia e de seu desempenho, estabelecendo os parâmetros para a administração interna da autarquia bem como os indicadores que permitam quantificar, objetivamente, a sua avaliação periódica.

Art. 20. O descumprimento injustificado do contrato de gestão implicará a exoneração do Diretor-Presidente, pelo Presidente da República, mediante solicitação do Ministro de Estado da Saúde."

32. Consta dos autos (fls. 69/140) cópia do relatório anual de execução do contrato de gestão. No quadro 9 (fls. 98/99) constam os indicadores e metas do termo aditivo àquele instrumento contratual. Pelo quadro, das metas estabelecidas para os 20 indicadores pactuados, 16 foram cumpridas, 2 foram parcialmente cumpridas e 2 não foram cumpridas.

33. Contudo, a análise realizada pela SFC junto às fichas de avaliação das metas do termo aditivo ao contrato de gestão (fls. 262/63) constatou, no entanto, que das metas previstas, foram alcançadas somente $65 \%$, conforme indicado no quadro seguinte.

34. Em sua percuciente análise, a SFC ponderou que algumas metas, a despeito de a entidade considerar cumprida, estavam apenas parcialmente cumpridas, conforme os próprios documentos acostados nos autos (fls. 100/36).

35. O quadro seguinte preparado por minha assessoria resume a situação em tela.

\begin{tabular}{|l|l|l|}
\hline \multicolumn{1}{|c|}{ Metas } & \multicolumn{1}{|c|}{ Anvisa } & \multicolumn{1}{|c|}{ SFC } \\
\hline $\begin{array}{l}1 \text { - processamento de excedente de plasma } \\
\text { de qualidade }\end{array}$ & Cumprido & $\begin{array}{l}\text { Cumprido } \\
\text { parcial }\end{array}$ \\
\hline $\begin{array}{l}4 \text { - \% de hospitais sentinela encaminhando } \\
\text { notificações de eventos adversos nas áreas } \\
\text { de fármaco, tecno e hemovigilância }\end{array}$ & $\begin{array}{l}\text { Cumprido } \\
\text { parcial }\end{array}$ & $\begin{array}{l}\text { Cumprido } \\
\text { parcial }\end{array}$ \\
\hline $\begin{array}{l}9 \text { - tempo de conclusão do processo de } \\
\text { registro de medicamentos genéricos }\end{array}$ & Não cumprido & Não cumprido \\
\hline $\begin{array}{l}10 \text { - tempo de conclusão do processo de } \\
\text { registro de similares }\end{array}$ & Não cumprido & Não cumprido \\
\hline $\begin{array}{l}13 \text { - tempo de conclusão do processo de } \\
\text { registro de produtos para saúde }\end{array}$ & $\begin{array}{l}\text { Cumprido } \\
\text { parcial }\end{array}$ & $\begin{array}{l}\text { Cumprido } \\
\text { parcial }\end{array}$ \\
\hline $\begin{array}{l}15 \text { - avaliação toxicológica para o processo } \\
\text { de registro de agrotóxicos }\end{array}$ & Cumprido & $\begin{array}{l}\text { Cumprido } \\
\text { parcial }\end{array}$ \\
\hline $\begin{array}{l}18 \text { - \% de avaliação técnica das metas } \\
\text { pactuadas nos Termos de Ajuste e Metas } \\
\text { com os estados }\end{array}$ & Cumprido & $\begin{array}{l}\text { Cumprido } \\
\text { parcial }\end{array}$ \\
\hline
\end{tabular}


36. Não constam dos autos elementos que evidenciem haver correlação entre as metas das ações e programas constantes do orçamento da entidade e as metas estabelecidas no contrato de gestão. A ausência dessa correlação impossibilita a análise a compatibilidade da execução orçamentária e realização das respectivas metas físicas com o cumprimento das metas contratuais.

37. A esse respeito, a SFC registra em seu relatório (fl. 261) que a maior concentração das ações do termo aditivo ao contrato de gestão encontra-se no programa "Vigilância Sanitária de Produtos e Serviços", o qual representa $41 \%$ da execução total da agência e cujo percentual de execução perante a dotação autorizada alcança $96 \%$ (fl. 14).

38. Consigna, aquele órgão de controle interno, que existem problemas de conformação das medidas e padrões definidos para o programa em tela.

40. Indica, também como causas do não-cumprimento integral de metas, de maneira geral, deficiência em recursos humanos e carências no tratamento de bancos de dados (fl. 262). Para cada "ponto crítico" emitiu os seguintes comentários (fls. 262/3):

[...]

41. A Anvisa não foi chamada a manifestar-se sobre o cumprimento parcial das metas estabelecidas no contrato de gestão.

42. Tampouco há registro nos autos de que o desempenho da agência tenha sido submetido a avaliação por parte do órgão supervisor segundo os termos do contrato de gestão e conforme Portaria Conjunta MS/Anvisa n ${ }^{\circ}$ 174/2000, então vigente.

43. A atuação do órgão supervisor é requisito essencial para funcionamento da cadeia de controle, motivo pelo qual proponho emissão de alerta ao Ministério da Saúde, conforme descrevo em bloco argumentativo específico desta proposta de deliberação.

44. Entendo também que, em futuros processos de contas onde se avalia a gestão da entidade, o alcance das metas e resultados institucionais contemplados no contrato de gestão deve ser objeto de exame por parte da unidade técnica. [...]

Em decorrência da discrepância da avaliação entre os relatórios emitidos pela Secretaria de Fiscalização de Controle Interno - SFC, órgão da Controladoria Geral da União e da Comissão de Avaliação da Anvisa, o TCU entendeu que a agência não possuía os instrumentos necessários para que a Comissão realizasse de fato a avaliação do contrato, o que acarretou a desconsideração do relatório emitido por essa, conforme consta na decisão do julgado:

9.15. determinar à Secretaria Executiva do Ministério da Saúde em conjunto com a Secretaria de Vigilância em Saúde/MS e Agência Nacional de Vigilância Sanitária (Anvisa) que implemente condições necessárias ao cumprimento do disposto na cláusula sexta do Contrato de Gestão da Anvisa, bem como na Lei $n^{\circ} 9.782 / 1999$, com vistas a realização do acompanhamento efetivo, bem como da avaliação, semestral e anual, do cumprimento das metas pactuadas no acordo firmado, de forma a atuar preventiva e tempestivamente e, prin- 
cipalmente, solucionar eventuais problemas e gargalos que possam impactar os resultados esperados;

9.16. recomendar à Agência Nacional de Vigilância Sanitária (Anvisa) que avalie a possibilidade de compatibilizar as metas apostas no contrato de gestão com aquelas definidas para os programas orçamentários da entidade;

9.17. determinar à $4^{\mathrm{a}}$ Secex que avalie o atingimento das metas e resultados institucionais contemplados no contrato de gestão quando da avaliação dos relatórios de gestão e das contas da Agência Nacional de Vigilância Sanitária (Anvisa);

O terceiro julgado transcrito é do TCE/SP, que aprecia as contas de uma OS que administrava o Hospital Geral de Pedreira. Na auditoria do tribunal foi apontada a falta do relatório conclusivo de avaliação. Instada a se manifestar, a Secretaria de Estado da Saúde apresentou justificativas que foram aceitas pelo sodalício, aprovando as contas, mas com a ressalva da necessidade a juntada do relatório de avaliação:

\begin{abstract}
Vistos, relatados e discutidos os autos.
Pelo voto do Substituto de Conselheiro Pedro Arnaldo Fornacialli, Relator, bem como pelo do Conselheiro Renato Martins Costa, Presidente em exercício, e do Substituto de Conselheiro Sérgio Ciquera Rossi, a e. $2^{\text {a }}$ Câmara, em sessão de 9 de fevereiro de 2010, nos termos do artigo 33, incisoI, da Lei Complementar $n^{\circ} 709 / 93$, decidiu julgar regular a prestação de contas referente aos recursos repassados, no ano de 2006, pela Secretaria de Estado da Saúde à Associação Congregação Santa Catarina, quitando-se os responsáveis e liberando-se o órgão beneficiário para novos recebimentos.

Determinou, outrossim, que, no prazo de 30 (trinta) dias, a contar do trânsito em julgado desta decisão, seja juntado aos autos o relatório conclusivo devidamente assinado pelo Presidente da Comissão de Avaliação. ${ }^{10}$
\end{abstract}

Nos três julgados citados, pode-se observar que o relatório da avaliação do contrato de gestão assume sempre a posição de fato-causa, que implica na emissão de um juízo de valor, o julgamento das cortes de contas, o fato-efeito, ou seja, formalizando " $\mathrm{D}(\mathrm{S} \rightarrow \mathrm{P})$ " (deve ser que $\mathrm{S}$ implique $\mathrm{P})$.

\title{
7 Conclusão
}

No dia a dia da prática jurídica é comum que o operador do Direito, por diversos motivos que fogem ao escopo do artigo, deixe de observar a influência de outros saberes na seara jurídica, cuidando apenas de questões dicotômicas da modalidade legal/ilegal.

10 TCE/SP, TC-017422/026/08, relator Conselheiro Robson Marinho. DOE 17-3-2010 
Possuir o mínimo de domínio sobre lógica jurídica é obrigação do operador do Direito, para evitar tantos erros grosseiros na apreciação jurídica de diversos atos da Administração.

Na questão dos contratos de gestão, matéria nova no sistema jurídico brasileiro, para a solução de muitas controvérsias faz-se necessária a realização de raciocínios como o demonstrado para, assim, separar o joio do trigo e dar segurança ao gestor da coisa pública quando tiver que tomar decisões que impliquem diretamente na eficiência e eficácia de uma política pública, que, no caso específico da Saúde, trata do bem maior protegido pela Magna Carta: a vida.

Os relatórios de avaliação são instrumentos que servem como conectores entre o mundo do "ser" e do "dever ser", gerando efeitos no segundo, que acarretam consequências no primeiro, especificamente quando há redução no valor pago ou repactuação de metas, em razão de recomendações constantes do relatório.

Por fim, pelo entendimento exposto nos julgados transcritos no presente artigo, observa-se que o relatório de avaliação passou a ser a peça chave não só para a questão envolvendo os efeitos financeiros do contrato, mas, também, para o julgamento das contas na corte de contas, ou seja, é o fato-causa implicando no fato-efeito.

\title{
Evaluation of a management contract: When reality meets the ideal -A legal-logical outlook of an instrument of the Management Science
}

\begin{abstract}
This paper aims to address, from the point of view of logicalsemantic, the evaluation report of management contracts signed between the government and social organizations, especially health care in the State of Goiás, performing entanglement, through legal logic, between the report and its effects, demonstrating that the report represents true reality ("being") as the effects represent the ideal reality ("ought") and therefore the connector between the two worlds.
\end{abstract}

Keywords: Management contract. Report rating. Administration. 


\section{REFERÊNCIAS}

ALBUQUERQUE, Pedro Sotero de. As organizações sociais (OS) e as organizações da sociedade civil de interesse público (OSCIP). 2008. 99 f. Dissertação (Mestrado em Direito)-Pontifícia Universidade Católica de São Paulo, São Paulo, 2008. Disponível em: < http://www. sapientia.pucsp.br//tde_busca/arquivo.php? codArquivo=7323 $>$. Acesso em: 22 mar. 2012.

ALMEIDA. Vicente de Paulo. Avaliação de programas sociais: de mensuração de resultados para uma abordagem construtivista. Pesquisas e Práticas Psicossociais, São João del-Rei, MG, v. 1, n. 2, dez. 2006. Disponível em: $<$ http://www.ufsj.edu.br/portal-repositorio/File/revistalapip/VicenteAlmeida.pdf $>$. Acesso em: 22 mar. 2012.

CARVALHO, Aurora Tomazini de. Teoria geral do direito: o construtivismo lógico-semântico. 2009. 623 f. Tese (Doutoramento em Direito)-Pontifícia Universidade Católica de São Paulo, São Paulo, 2009. Disponível em: $<$ http://www.sapientia.pucsp.br//tde_busca/arquivo. php? $\operatorname{cod}$ Arquivo $=9427>$. Acesso em: 22 mar. 2012.

CRUZ, Marly Marques. Avaliação de programas de prevenção de DST/ AIDS para jovens: estudo de caso numa organização governamental e numa organização não-governamental do Município do Rio de Janeiro. 2006. 234 p. Tese de Doutoramento. FIOCRUZ, Rio de Janeiro. Disponível em $<$ http://bvssp.icict.fiocruz.br/lildbi/docsonline/get.php?id=1023 $>$. Acesso em 23 mar. 2012.

DI PIETRO, Maria Sylvia Zanella. Direito administrativo. 18. ed. São Paulo: Atlas, 2005.

. Parcerias na administração pública: concessão, permissão, franquias, terceirização, parceria público-privada e outras formas. 8. ed. São Paulo: Atlas, 2011.

MINAYO, Maria Cecília de Souza. Conceito de avaliação por triangulação de métodos. In: MINAYO, Maria Cecília de Souza (Org). Avaliação por triangulação de métodos: abordagens de programas sociais. Rio de Janeiro: Fiocruz, 2005. p. 19-51. 
RABENHORST, Eduardo Ramalho. Ser e dever ser na teoria kelseniana do direito. Revista de Direito e Liberdade, Mossoró, RN, v. 1, n. 1, p. 94-103, 2005. Disponível em: < http://www.esmarn.tjrn.jus.br/ revistas/index.php/revista_direito_e_liberdade/article/view/218/248>. Acesso em: 31 mar. 2012.

眉 Recebido: abril/2012. Aprovado: junho/2013. 